\title{
Patrimônio Cultural da Saúde: uma década de reflexão e atuação sobre o campo
}

\section{Health Cultural Heritage: a decade of reflection and action on}

\section{the field}

\author{
Recebido em: 04/01/2019 \\ Aceito em: 10/01/2019 \\ Gisele Sanglard ${ }^{1}$ \\ Renato da Gama-Rosa Costa²
}

\begin{abstract}
Resumo:
Este artigo se propõe a fazer um balanço dos dez anos em que o patrimônio cultural da saúde se estabeleceu como tema de pesquisa em diversas instituições de ensino e pesquisa no Brasil. Para tal, será dividido em três partes: a primeira, reflete sobre a transformação da área do patrimônio no país; a segunda, pretende fazer um breve balanço historiográfico acerca dos estudos sobre o patrimônio cultural da saúde no Brasil; e a terceira e última parte, procurará analisar o papel dos cursos de pós-graduação e os caminhos que teses e dissertações estão apontando para a temática. Longe de pretender ser um estudo exaustivo, este artigo pretende apresentar uma breve reflexão sobre o tema.
\end{abstract}

Palavras-chave: Patrimônio Cultural da Saúde; história da saúde; arquitetura e saúde.

\section{Abstract: \\ This article aims to make an analysis of the ten years in which the cultural heritage of health has been established as a research theme in several teaching and research institutions in Brazil.To do this, the article will be divided into three parts: the first one, reflects on the transformation of the patrimony area in Brazil; the second, intends to make a brief historiographic balance about the studies on the cultural heritage of health; and the third and final part, will seek to analyze the role of postgraduate courses and the paths that theses and dissertations are pointing to the theme. Far from}

\footnotetext{
${ }^{1}$ Doutora em História das Ciências e da Saúde, Pesquisadora da Fiocruz: gisele.sanglard@fiocruz.br

2 Doutor em Urbanismo, Pesquisador da Fiocruz: renato.gamarosa@fiocruz.br
} 
Há dez anos, em 2008, saía publicado pela Editora Fiocruz o livro História da saúde no Rio de Janeiro: instituições e patrimônio arquitetônico. Organizado pelos pesquisadores Ângela Pôrto, Gisele Sanglard, Maria Rachel Fróes da Fonseca e Renato da Gama-Rosa Cosa, o livro consolidava uma pesquisa iniciada anos antes pela Casa de Oswaldo Cruz com objetivo de evidenciar e valorizar o Patrimônio Cultural da Saúde. O livro formado por cinco capítulos vem acompanhado por um CD com verbetes destinados a contar a história de instituições que fazem parte do Patrimônio Cultural da Saúde levando em consideração não só a história institucional ou seu patrimônio arquitetônico, mas também agregando, quando possível, os acervos integrados.

Tais pesquisas, realizadas de forma espontânea e por iniciativa de pesquisadores de história e de arquitetura e urbanismo da instituição, procuravam trazer um sentido para o que se começava a se delinear como uma preocupação com a identificação do que seria passível de ser um patrimônio próprio da área das ciências e da saúde. Para tanto, era necessário primeiramente identificar que instituições possuíam reconhecimento por seus atributos históricos, científicos e materiais, sobretudo arquitetônico e museográfico, traduzidos em ações oficias de proteção (fosse municipal, estadual ou federal) e quais ainda não, para, em um passo a seguir, merecer ações de salvaguarda e valorização patrimoniais.

O levantamento realizado serviu de reflexão para o livro lançado em 2008. Uma das conclusões a que se chegou, com a publicação, é que muito estava por se fazer em relação ao patrimônio específico das ciências e da saúde, reconhecendo ali uma atitude pioneira, cujo desafio também seguia a recomendação de um outro marco da conformação do campo: a publicação do documento-base fruto das discussões oriundas do Grupo de Trabalho História e Patrimônio Cultural da Saúde que se reuniu durante a 4aㅗ Reunião de Coordenação Regional da Biblioteca Virtual de Saúde (BVS) / $7^{0}$ Congresso Regional de Informação em Ciências da Saúde (CRICS), na cidade Salvador (BA), em 2005. Em linhas gerais, o encontro objetivava 
desenvolver-se de forma progressiva constituindo-se numa rede latinoamericana do Patrimônio Cultural da Saúde e, sobretudo, contribuir para a construção de identidades das instituições, dos profissionais da saúde e de seus principais agentes e movimentos sociais, ao reconhecerem nela elementos de grande relevância simbólica e material no seu campo de atuação. Ao mesmo tempo, servirá à interação do Estado, da sociedade e dos indivíduos no processo de reconstrução crítica do passado por meio de produtos/serviços que proporcionem para públicos amplos o encontro com passagens relevantes da história da saúde e referenciem importantes registros de sua memória (TERMO DE CONSTITUIÇÃO..., p. 6).

O evento estabeleceu um forte laço de trabalhos em prol do que se cunhava naquele momento como Patrimônio Cultural da Saúde entre os governos do Brasil e do Chile, cujas ações de salvaguarda de seu patrimônio científico e da saúde partiu diretamente do Ministério da Saúde local, sendo tal país tido como referência no tema e que até hoje mantém uma unidade administrativa atuante nas ações de proteção patrimonial e de salvaguarda.

Entre os objetivos do documento, figurava ações que contribuíssem para a formulação e implementação de políticas; tornassem visível e disponibilizassem para o setor saúde um conjunto de competências institucionais estabelecidas; promovessem a cooperação técnico-científico no âmbito de programas, projetos e atividades, bem como formas de capacitação de profissionais para o desempenho das atividades técnico-científicas, voltados para a identificação, recuperação, conservação e valorização e do Patrimônio Cultural da Saúde. Visava, ainda, promover a pesquisa histórica sobre a saúde e as ciências da saúde e estimular a aproximação entre as instituições públicas e privadas detentoras e/ou custodiadoras de registros e bens constitutivos do Patrimônio Cultural da Saúde, com ações em desenvolvimento nos países da América Latina e Caribe, assim como junto a países africanos e asiáticos de língua portuguesa ${ }^{3}$ e espanhola e países ibéricos.

Uma forma de se iniciar essas ações foi por meio da realização de uma pesquisa acerca do patrimônio da saúde no Rio de Janeiro, cujo livro foi lançado no

\footnotetext{
${ }^{3}$ Em relação a Portugal, duas pesquisas iniciadas recentemente sobre o patrimônio hospitalar português, confirma o interesse desse país no tema, a saber,CUCa_RE: Curar e Cuidar_reabilitar, coordenado por Ana Tostões e Paulo Providência eHospitalis - Arquitetura hospitalar em Portugal nos alvores da Modernidade: identificação, caraterização e contextualização, coordenado por Joana Balsa de Pinho, com pesquisadores brasileiros no grupo. Lisboa particularmente presencia uma preocupação com a preservação do que se chama naquela cidade de Colina da Saúde, devido ao projeto de construção do Hospital de todos os Santos nos arredores da capital lusitana, que impõe a destruição de tradicionais hospitais situados na Colina de Sant'Ana. A proposta, apresentada em 2013 à Câmara Municipal de Lisboa, segundo parecer da Seção de História da Medicina da Sociedade de Geografia de Lisboa, propõe "o mais completo 'branqueamento' da história hospitalar da Colina de Sant'Ana" (PARECER..., 2014)
} 
âmbito das comemorações dos duzentos anos da chegada da Corte Portuguesa ao Brasil, em 2008. Essa iniciativa criou frutos e foi expandida posteriormente para outras capitais brasileiras (Porto Alegre, Florianópolis, São Paulo, as capitais mineiras - Ouro Preto e Belo Horizonte, as capitais de Goiás - cidade de Goiás e Goiânia, Salvador, Recife, Belém e Manaus). O inventário reunido em todas as pesquisas foi, na sua grande maioria, transformado em livro; e os verbetes fazem parte da Biblioteca Virtual História e Patrimônio Cultural da Saúde(BVSHPCS). Estes inventários também abriram caminhos para teses e dissertações nas mais diversas áreas do conhecimento, cujos resultados veremos mais detalhadamente a frente neste artigo.

Ao longo destes dez anos, os estudos sobre patrimônio no Brasil cresceram e o patrimônio cultural da saúde se consolidou como objeto de análise e, neste processo, a expansão dos cursos de pós-graduação no Brasil tiveram papel fundamental.

Este artigo tem, então, como objetivo, fazer um balanço destes dez anos em que o patrimônio cultural da saúde se estabeleceu como tema de pesquisa em diversas instituições de ensino e pesquisa no Brasil. Para tal, este artigo será dividido em três partes: a primeira, reflete sobre a transformação da área do patrimônio no país; a segunda, pretende fazer um breve balanço historiográfico acerca dos estudos sobre o patrimônio cultural da saúde no Brasil; e a terceira e última parte, procurará analisar o papel dos cursos de pós-graduação e os caminhos que teses e dissertações estão apontando para a temática. Longe de pretender se um estudo exaustivo, este artigo pretende apenas apresentar uma breve reflexão sobre o tema.

\section{As transformações da área do patrimônio no Brasil}

Antes restrito a edificações e monumentos históricos,o debate contemporâneo sobre o patrimônio, no Brasil,abre espaço para diferentes objetos de diferentes épocas e procedências, manifestações culturais e religiosas, sítios, memoriais, parques, entre outras formas de expressão do tangível e do intangível. Tal discussão acrescenta ainda questões relativas à ética na preservação cultural, à inserção de novos suportes documentais e sua preservação, a patrimonialização dos documentos originais e o papel social dos museus, arquivos, bibliotecas e centros de documentação.

Considera-se que o maior desafio colocado às disciplinas do patrimônio história, arquitetura, arquivologia, arqueologia, museologia e conservação -seja o 
tema da valorização da perspectiva histórica dos objetos patrimonializados, presente em diversos estudos sobre inventários, atribuição de valor ou mesmo na sua gestão. Observe-se que o enraizamento dos bens patrimoniais na longa duração, e a escolha de sua permanência para o futuro, depende da história enquanto disciplina, uma vez que as operações históricas promovem escolhas, produzem hierarquias, e constroem valores fundamentais para os julgamentos responsáveis por permitirem a sobrevivência desses bens.

\begin{abstract}
O patrimônio se situa entre a memória e a história. Ora, nós vivemos um tempo de memória triunfante e invasiva. É preciso que ela [a memória] seja [...] informada por um estudo mais objetivo e mais científico que tem na história seu principal ator, mas na qual todas as disciplinas do patrimônio podem ter seu papel. Acredito que a apresentação da memória, a reação à memória devem ser uma das atividades, um dos deveres, um dos sujeitos de reflexão das disciplinas do patrimônio. (LE GOFF, 1997,p.122)
\end{abstract}

Num contexto no qual as fontes para o estudo histórico são constantemente ampliadas, e considerando as transformações pelas quais o conceito de patrimônio vem passando, a noção de referência cultural ganha importância na constituição de um olhar mais abrangente para as práticas de preservação patrimoniais. Assim, ao lado das fontes mais tradicionais, somam-se os objetos que fazem parte do cotidiano das pesquisas em instituições científicas, que podem estar localizados no interior dos laboratórios, nas universidades e centros de pesquisa e desenvolvimento tecnológico, o que os torna importantes para o conhecimento da história das ciências e de seu patrimônio. Conhecê-los, identificá-los e inventariá-los se tornam as ações principais que envolvem o desbravamento deste 'novo' patrimônio, que necessita ser estudado, sobretudo pelo caráter de 'novidade' que apresenta - os primeiros estudos datam da década de 1990 na Holanda, Inglaterra e Austrália. Desta forma, conceituar, tomar como objeto e preservar o Patrimônio Cultural das Ciências e da Saúde se torna uma tarefa desafiadora.

A inserção de novos elementos no rol de bens considerados de valor cultural como os vinculados às atividades na área da saúde - vem gerando debates. $\mathrm{Na}$ França, por exemplo, onde a tuberculose se caracterizou por ceifar muitas vidas na primeira metade do século $\mathrm{XX}$, foram construídos diversos sanatórios por todo território, respondendo às necessidades terapêuticas da doença e agregando o mais moderno da arquitetura e da engenharia. Contudo, essas edificações eram percebidas 
pela população como espaço da morte e, pelos médicos, como demonstração do fracasso da ciência médica, uma vez que a tuberculose só passou a ser curada, de fato, na segunda metade do século passado, com o advento da penicilina (Creminitzer, 2005). Diante de referenciais que suscitam sentimentos tão negativos ou contraditórios nos grupos a eles relacionados, como torná-los bens cujo valor está ligado a própria transformação da cultura médica e, em maior medida, aos contextos sociais, culturais, políticos e econômicos pelos quais a população francesa passou ao longo do século $X X$ ? Tal é o desafio a ser enfrentado.

Transpondo a questão para os bens culturais provenientes das práticas da área da saúde pública no Brasil, chegamos à mesma constatação: qual o significado que possuem para os diferentes atores e grupos sociais? Como preservá-los? Tal como o patrimônio científico, o conjunto de bens da saúde é desconhecido, cujas dimensões merecem ser notadas. Dentre esses aspectos, destaca-se o fato da experiência cultural na saúde ser, necessariamente, multifacetada e multidimensional, por envolver o sofrimento individual e coletivo, por um lado, e, por outro, envolver as expectativas de cada indivíduo diante do tempo, da vida e do mundo, ao mesmo tempo em que tem a capacidade de representar as lutas e conquistas coletivas em direção a melhores condições de existência. É imprescindível, portanto, promover os meios para a expressão cultural, o registro, a preservação, a difusão e atualização permanente dessa experiência histórica comum.

Pioneira no processo de preservação e disseminação da memória e do patrimônio documental e arquitetônico relacionado às ciências e a saúde no Brasil, a Casa de Oswaldo Cruz (COC) se dedica à preservação da memória da Fundação Oswaldo Cruz e às atividades de pesquisa, ensino, documentação e divulgação da história da saúde pública e das ciências biomédicas no Brasil. Sob sua responsabilidade, se encontra o acervo mais expressivo do país sobre os processos políticos, sociais e culturais da saúde. Este acervo contempla fotografias, filmes, documentos textuais, peças museológicas e depoimentos orais que remontam ao fim do século XIX, além dos arquivos pessoais de cientistas e sanitaristas que marcaram a história da instituição.

Entre suas funções, assumiu a tarefa de organizar estruturas e processos que viabilizem a utilização dos acervos da Fiocruz, garantindo sua relação de troca com outros sistemas e possibilitando ampliar seu uso social e a geração de pesquisas nos 
campos da história, da memória e da preservação das ciências e da saúde. Ao longo do tempo, esses acervos de conhecimento se transformaram em bens culturais que compõem hoje um valioso patrimônio científico brasileiro reconhecido pelas agências públicas e a sociedade. Ao mesmo tempo, tais acervos vêm possibilitando a realização de pesquisas em articulação à prática profissional nos campos da arquivologia; documentação e informação; divulgação científica; educação em ciências; e arquitetura e urbanismo em saúde.

As interfaces e o diálogo entre as diversas áreas de pesquisa da COC têm contribuído para potencializar o alcance e a importância social de seu trabalho, se destacando, entre outros, na constituição da Rede Brasil de Patrimônio Cultural da Saúde, coordenada por pesquisadores da própria instituição, que no ano de 2018 completou um década de atividade, com o objetivo de produzir o Inventário Nacional do Patrimônio Cultural da Saúde: bens edificados e acervos, abrangendo o Estado do Rio de Janeiro e algumas capitais brasileiras, conforme já adiantado anteriormente. Esse trabalho resultou na produção de volumes dedicados ao patrimônio cultural da saúde para o Rio de Janeiro e Rio Grande do Sul (2008); Bahia, Minas Gerais e São Paulo (2011); Santa Catarina (2012), e Goiás (2017). Os verbetes que acompanham os livros, em CD encartados, foram, também, disponibilizados online na BVSHPCS ${ }^{4}$, incluindo as cidades de Belém, Manaus, Recife e algumas instituições da cidade de Niterói.

A realização das pesquisas em tais capitais partia da metodologia adotada para o Rio de Janeiro, cujo período histórico percorreu de 1808 a 1958. O primeiro ano se referia à chegada da Corte Portuguesa ao Brasil, e o ano de 1958 à inauguração do Hospital da Lagoa, importante marco da arquitetura hospitalar moderna no Rio de Janeiro. Lançado em 2008, o livro participava então das comemorações, tendo recebido o selo da Prefeitura da Cidade do Rio de Janeiro. As instituições levantadas incluíam desde hospitais a casas de saúde e institutos de pesquisa e de educação em áreas da saúde. Nos verbetes produzidos, procurou-se descrever a história de cada instituição; seus proprietários; as diversas denominações que a instituição foi amealhando ao longo de história; e, por fim, a constituição de suas sedes, em que se procurou revelar os valores arquitetônicos e patrimoniais, bem como formas de proteção.

\footnotetext{
${ }^{4} \mathrm{O}$ endereço da BVSHPCS é http://hpcs.bvsalud.org/vhl/temas/patrimonio-cultural/
} 
Os demais inventários seguiram tal metodologia, mas deixava ao encargo de cada coordenador da respectiva capital uma certa liberdade de período de pesquisa e, também, de objeto, dependendo de particularidades locais. Por exemplo, a pesquisa realizada em Santa Catarina incorporou ao inventário as fortalezas usadas durante os períodos de quarentena do século XVIII, na cidade de Florianópolis. Em Manaus, a investigação incluiu instituições criadas até o final do século XX e os cemitérios.

Os coordenadores dos inventários nas capitais se constituíram de historiadores e arquitetos, envolvendo pesquisadores locais em nível de adjunto e de assistente, podendo ser jovens doutores ou mesmo estudantes de mestrado e graduação. A ideia de envolver instituições de ensino foi de criar núcleos de pesquisa locais, contribuindo para consolidar o campo de conhecimento acerca das instituições de saúde, sua história, sua arquitetura e seu patrimônio.Essa nucleação pode ser percebida por meio das teses e dissertações defendidas nos programas de origem dos pesquisadores envolvidos, como veremos mais adiante.

\section{Breve balanço historiográfico acerca dos estudos sobre o patrimônio cultural da saúde no Brasil}

De um modo geral, podemos dizer que os estudos sobre o patrimônio cultural da saúde no Brasil estão concentrados em três grandes eixos complementares e que têm na história das instituições o ponto de convergência - o que não significa que não possam haver outros não indicados neste artigo. São eles: história das instituições, com ênfase nos estudos sobre as instituições de ciência e de saúde e os hospitais; história, memória e patrimônio,com maior enfoque na preservação e conservação de acervos, como o de instrumentos científicos, por exemplo, mas sem deixar de abordar a história das instituições de guarda de tais acervos; e arquitetura e saúde, com destaque para a história da arquitetura no contexto da história das intuições.

Apontar marcos iniciais é sempre problemático, comete-se sempre injustiças. Sem dúvida podemos iniciar esta análise a partir da publicação do artigo "Direções e traçados da assistência hospitalar no Rio de Janeiro (1923-31)" por Gisele Sanglard e Renato Gama-Rosa Costa no primeiro quadrimestre de 2004, que se propôs a pensar a construção de três novos hospitais na cidade do Rio de Janeiro na década de 1920. Nesse artigo, história social, biografia, história das ciências (arquitetura e medicina) se 
entrecruzaram e a construção de hospitais ganhou maior evidência (Sanglard e Costa, 2004). Os autores seguiram o caminho iniciado anos antes por Jaime Benchimol em Manguinhos do sonho a vida (Benchimol, 1990) e a proposição de Lindsay Grashwanna introdução de The hospital in history, onde o hospital é percebido como microcosmo da sociedade (Grashwan e Porter, 1989).

A publicação desse artigo abriu caminho para a doação, por parte da família do arquiteto responsável, do acervo iconográfico de Adelstano Soares de Mattos Porto d'Ave. A primeira leva doada constava de cerca de uma centena de negativos de vidro que possibilita ao estudioso conhecer a concepção de cada projeto em que Porto d'Ave se envolveu; a segunda leva, complementa a primeira e ajuda a compreender os estudos realizados para cada um dos hospitais por ele projetado. Não eram mais apenas os hospitais, mas também o acervo (Sanglard, Costa e Mello, 2007; Sanglard e Costa, 2012).

Ana Venâncio e Gisélia Potengyao organizarem o livro $O$ asilo e a cidade histórias da Colônia Juliano Moreira (Venâncio e Potengy, 2015) também contribuem para a valorização do patrimônio da saúde ao reunirem diversos trabalhos que analisam vários aspectos da colônia: desde a ocupação do espaço físico e suas transformações, aos seus edifícios, a experiência de vida na colônia (médica e religiosa) e o saber médico. Ao dar uma ideia de conjunto, a obra contribui para o conhecimento da história da instituição.

Uma ressalva deve ser feita: fazer uma história institucional não significa a patrimonizalização da instituição. A Colônia Juliano Moreira já tem seu núcleo histórico tombado ${ }^{5}$, mas o artigo de Sanglard e Costa acima referenciado serviu de base para o processo de tombamento do Hospital Universitário Gaffrée e Guinle (Unirio) solicitado pela comunidade hospitalar ao atual Instituto Pereira Passos da PMCRJ.

Na mesma ótica, podemos considerar que o estudo da história e da construção do antigo sanatório de Curicica, realizado por Dilene Nascimento, Renato da GamaRosa Costa,e outros, antecipou, de certa forma, o processo de tombamento, iniciado no ano seguinte, pela Prefeitura da Cidade do Rio de Janeiro. Suas instalações originais, dispostas em pavilhões, estavam então ameaçadas de demolição. O estudo realizado colaborou para se valorizar a arquitetura feita por um dos mestres de nossa

${ }^{5}$ Ressalte-se que o tombamento do Núcleo Histórico Rodrigues Caldas da Colônia Juliano Moreira restringe-se às edificações da antiga Fazenda do Engenho de Dentro, datada do período colonial, que foram adaptados para receber os primeiros internos da colônia. 
arquitetura moderna, Sérgio Bernardes (1944-2007) e, assim, contribuir para sua preservação, cujo processo se acha ainda inconclusivo (Nascimento, Costa et all, 2002).

Como Juliane Serres chama atenção, os hospitais "devido a concepções patrimoniais restritas, fruto de contextos históricos específicos, por muito tempo sequer constavam entre os bens dignos de preservação" (Serres, 2015: 3). A autora ressalta que o Iphan tombou um total de 14 edifícios pertencentes a instituições de assistência à saúde nos estados do Rio de Janeiro, Minas Gerais, Bahia e Pernambuco - dos quais oito no livro de Belas Artes e outros seis no de Belas Artes e Histórico.

A dificuldade desta valorização encontra-se na vinculação do hospital com a morte e a dor, e não como lugar da saúde, da vida. Esta mudança de perspectiva, de olhar, é muito recente - data do pós $2^{\text {a }}$ Guerra Mundial com a possibilidade de cura de inúmeras doenças que até então eram apenas controladas, sem contar o próprio desenvolvimento da medicina. Ou como diz Creminitzer para o caso dos sanatórios franceses, conforme já referido anteriormente: como reconhecer valor a edificações que trazem na lembrança a morte de algum parente ou amigo de tuberculose; ou mesmo o fracasso da medicina? (Creminitzer, 2005).

$\mathrm{Na}$ contramão desta pergunta vemos o processo de patrimonialização de diversos leprosários pelo Brasil. Lugar de exclusão e de segregação, os leprosários construídos no Brasil a partir da década de 1920 e que ganham força a partir do Estado Novo, com as ações do Ministério da Educação e Saúde, estão passando por um processo de patrimonialização. Tal movimento insere-se em outro momento do entendimento do Patrimônio, onde se "antes apenas algumas memórias [que] eram reivindicadas como legítimas e, portanto, patrimonializáveis, contemporaneamente há uma dilatação desses referenciais" (Serres e Borges, 2015: 256). Para Juliane Serres e Viviane Borges, a patrimonialização destes espaços procura "garantir a preservação como uma forma de reconciliação com um passado doloroso, que ainda reverbera no social" e, sob esta perspectiva,

o trabalho de preservação proporciona a patrimonializacão de locais marcados pelo sofrimento, os quais são convertidos em monumentos em toda a polissemia da palavra, como locais de lembrança, advertência, como testemunhos dos tempos passados, como símbolo, como antídoto contra o esquecimento. (Serres e Borges, 2015, p. 256) 
Apesar de apontarem diversas instituições em processo de patrimonialização, as autoras estudam os casos mais adiantados: a Colônia de Itapuã, no Rio Grande do Sul, e a Santa Tereza, em Santa Catarina. Partindo de processos diversos - enquanto Itapuã o movimento partiu da direção, em Santa Tereza partiu dos funcionários - a sobrevivência dos lugares de memória criados em ambas as instituições também seguiu caminhos diversos. O Centro de Documentação e Pesquisa (Cedope) da Colônia de Itapuã foi criado em 1999 e sobreviveu até 2002; já o Museu criado em Santa Tereza para lembrar a história da Colônia e de seus moradores continua funcionando e é preservado pelos funcionários e os próprios internos.

\begin{abstract}
Quanto aos acervos, o Cedope preserva uma documentação administrativa e da saúde pública, além de um banco de dados com entrevistas e um acervo de fotografias. Os objetos tridimensionais formam a menor parte do acervo. No museu do Santa Teresa é exatamente o contrário, pois o maior acervo é de objetos e fotografias relacionados à instituição. A documentação administrativa e a médica não estão preservadas no museu, ficando a cargo da Secretaria de Estado da Saúde, que atualmente cuida da digitalização dos prontuários dos pacientes que por lá passaram ao longo dos anos. Guardadas as diferenças, a preservação desses acervos permite conhecer e compreender um pouco da vida nessas instituições. (Serres e Borges, 2015, p. 259)
\end{abstract}

Os exemplos são múltiplos e não cabe, nos limites deste artigo enumera-los todos. Fica apenas o questionamento proposto pelas autoras: lugar de memória para quem? As experiências analisadas por elas mostram que se o movimento não partir da própria comunidade, quer de funcionários, quer de moradores, a sobrevivência destes lugares de memória pode ficar prejudicada.

Este mesmo alargamento do conceito de patrimônio, que na nova relação do homem com o tempo passa a exercer um papel central para as sociedades atuais (Hartog, 2003), os objetos de ciência também passam a ser patrimonializados. Como Marcos Granato e Marta Lourenço chamam atenção, as primeiras pesquisas apontaram a necessidade de conhecer os objetos: "que constitui esse patrimônio, como está legalmente protegido e da possibilidade de utilização dos itens constituintes como fontes históricas" (Granato e Lourenço, 2010, p. 86). Um problema destacado por ambos é que muitas vezes os objetos científicos não são utilizados como fontes históricas, servindo apenas como ilustração. Tal dificuldade é atribuída à formação do 
historiador, que não o prepara para analisar tais instrumentos como fontes primárias de suas pesquisas.

Outro obstáculo percebido é o fato de que muitas vezes esses objetos estão sob guarda de instituições que não são vocacionadas para a sua preservação e pertencem à acervo de laboratórios científicos, não constituindo, a priori, itens patrimonializáveis ou mesmo passíveis de musealização.

A despeito dos problemas apontados, o conceito de patrimônio cultural da ciência e da tecnologia proposto por ambos os autores é bastante alargado e abrange todos os instrumentos utilizados para a produção de pesquisa científica e/ou desenvolvimento tecnológico. Para os autores,

\footnotetext{
devem ser consideradas como parte desse patrimônio as coleções arqueológicas, etnográficas e das ciências biológicas e da terra, nomeadamente mineralógicas, geológicas, botânicas, zoológicas e paleontológicas utilizadas para esse fim. Enfim, estamos no âmbito daqueles conjuntos de objetos, no amplo sentido do termo, que foram utilizados para produzir ciência e desenvolvimento tecnológico e que foram gerados a partir desses processos (Granato e Lourenço, 2010, p. 89).
}

Os autores apontam que grande parte desse acervo está disperso nas universidades públicas brasileiras, o que, para Emanuela Ribeiro, é um ponto desfavorável a eles. A autora argumenta que, atualmente, os museus universitários, "não costumam gerar capital científico e, por este motivo não recebem suficiente valorização no ambiente institucional universitário, estando sempre em situação de inferioridade na disputa por recursos humanos e materiais (Ribeiro, 2013)". Colocando, assim, em risco suas coleções e suas edificações, vide o caso recente do incêndio que danificou enormemente a edificação e destruiu boa parte da coleção do Museu Nacional no Rio de Janeiro no ano em que se comemorava 200 anos da criação da instituição. Foram destruídas as peças que estavam em exposição, quanto aquelas guardadas nas reservas técnicas do prédio principal; além dos gabinetes dos pesquisadores e documentos administrativos.

No que tange ao patrimônio arquitetônico, este já vem sendo estudado há mais tempo. Os hospitais, sobretudo aqueles do modernismo em arquitetura exercem fascínio sobre aqueles que se dedicam a estuda-los do ponto de vista da história da 
arquitetura, dos métodos construtivos e de sua implantação no espaço urbano. ${ }^{6}$ Esse foi, por exemplo, o caminho encontrado por Luiz Amorim e Cecília Ribeiro no artigo "O espaço hospitalar em dois tempos: o Pronto Socorro do Recife". No artigo os autores analisam tanto as questões políticas para sua construção - escolha do projeto arquitetônico e decisão de construção - como as questões urbanas, seu impacto no novo projeto urbano de Recife. Tais contendas fizeram com que o projeto se arrastasse por mais de 10 anos, entre as décadas de 1950 e 1960. Do ponto de vista arquitetônico, ressaltam a formação carioca dos arquitetos envolvidos no projeto e a forte inspiração no Hospital Sul América (atual Hospital da Lagoa) cujo projeto é assinado por Oscar Niemayer.

Para os autores, 0

projeto da principal unidade de atendimento de urgência de Pernambuco é um caso exemplar da relação entre os avanços nas ciências médicas e na arquitetura ao longo do século 20 , mas também revela a práxis política nacional, plena de intermitências e atropelos. (Amorim e Ribeiro, 2017)

Para o caso da Bahia, Nivaldo Andrade (2011) já apontava para um fato que é tratado por Luiz Amorim e Cecília Ribeiro (2017): a falta de arquitetos locais para desenvolvimento de projetos modernistas e a necessidade de contratação de escritórios da capital federal. Mais do que casos pontuais, ao que parece era uma característica da região, mesmo nas principais capitais como Salvador e Recife. Para o autor, as

edificações hospitalares e de assistência à saúde construídas na Bahia entre as décadas de 1930 e 1960 representaram uma importante contribuição tanto para a infraestruturação de Salvador e das principais cidades baianas quanto para o processo de consolidação da arquitetura moderna no Estado, servindo, inclusive, de referência para edificações com outros programas. (Andrade, 2011, p. 108)

Neste cenário ressaltam-se os Postos de Puericultura, os hospitais para tuberculosos, e hospitais gerais - estes vinculados às políticas do Ministério da

6 Fugindo dos trabalhos sobre o Modernismo na Arquitetura para a saúde, Cybelle Salvador Miranda dedica-se ao estudo do classicismo. As questões importantes como a política e a construção de edifícios próprios para instituições de saúde se faz presente igualmente em seus estudos (Miranda et all; 2015). Contudo, vale ressaltar o livro recém lançado pela autora em parceria com Renato da Gama-Rosa Costa acerca dos edifícios para saúde no Oitocentos (Miranda e Costa, 2018). 
Educação e Saúde sob gestão de Gustavo Capanema e a direção de João de Barros Barreto a frente do Departamento Nacional de Saúde. Contudo, conforme Nivaldo Andrade aponta, a ampliação da infraestrutura em saúde na Bahia ocorreu principalmente no governo do presidente Enrique Gaspar Dutra (1946-1951) e do governador Octávio Mangabeira (1947-1951).

Outra possibilidade de estudos em arquitetura e saúde vem sendo descortinada por Renato da Gama-Rosa Costa e Ana Albano Amora que são as pesquisas acerca dos hospitais pavilhonares, associado ao estudo das políticas públicas de criação de instituições que adotavam a terapia de isolamento de seus pacientes, mentais e/ou acometidos por tuberculose e hanseníase. Esta linha de investigação os insere em uma rede latino-americana sob liderança de pesquisadores da Universidade Nacional Autônoma do México (Costa e Amora, 2011, 2014, 2016 e 2018).

Tal como ocorre com os trabalhos de história das instituições, a maior parte dos trabalhos que se dedicam ao estudo do patrimônio arquitetônico poucos são aqueles que problematizam o patrimônio. Acabam por atuarem mais na questão da valorização do que propriamente na patrimonialização e salvaguarda de tais edificações, que são de responsabilidade dos órgãos de tutela e não das instituições de pesquisa. Tais trabalhos transformam-se em um grande inventário de bens que ajudam a contar a história da saúde no Brasil ea chamar a atenção para a questão patrimonial, sem, necessariamente, efetivar ações de proteção, o que esperamos ser uma meta a ser atingida em algum tempo próximo.

Nesse sentido, vale a pena ressaltar ainda dois trabalhos. O primeiro, escrito por Cybelle Salvador Miranda e Marcia Monteiro, faz o balanço historiográfico de diversas ações - projetos, artigos, seminários - acerca da temática do Patrimônio Cultural da Saúde (Miranda e Monteiro, 2017), e que se constitui uma importante fonte para se pensar esta temática. Para as autoras, 0

cuidado com o olhar o passado nos permite fazer o enquadramento da arquitetura enquanto projeto e cultura material, objeto de vários olhares e vivências, em que a atuação do projetista só recentemente foi consolidada, face aos diversos atores sociais intervenientes e aos significados construídos historicamente... (Miranda e Monteiro, 2017, p. 195) 
Sobretudo, as autoras ressaltam a necessidade de refletir sobre a não uniformização das soluções arquitetônicas tendo em vista a diversidade climática e morfológica do Brasil.

Outra possibilidade de análise é o estudo acerca do processo de tombamento de edificações de saúde, tal como o realizado por Priscila Miura (2015). Partindo do tombamento do chamado Quadrilátero da Saúde, pelo Conselho de Defesa do Patrimônio Histórico, Arqueológico, Artístico e Turístico (Condephaat) em 2005, a autora investiga a criação dos prédios que compõe o conjunto dos edifícios voltados para a saúde da Universidade de São Paulo - os que compõe o Hospital das Clínicas, o prédio da Faculdade de Medicina, da Faculdade de Enfermagem e de institutos de pesquisa. Ponto chave da análise é o tombamento do conjunto, abarcando diversas instituições com funções próprias. Para a autora,

\footnotetext{
Essa visão inter-relacional determina uma diferença entre os primeirostombamentos na área - pensados de maneira isolada e individual e o tombamento desse conjunto, criando uma rede de relações entre as instituições ali estabelecidas: os bens já protegidos e aqueles a serem tombados (Miura, 2015, p. 76).
}

Nivaldo Andrade nos coloca uma problematização ao final do artigo já referenciado e que dialoga com a discussão aqui proposta entre a valorização e a patrimonialização das instituições de saúde e suas edificações. Apesar de falar para o caso da Bahia, sua reflexão pode ser espraiada para o resto do país e ressalta a importância dos trabalhos de valorização do patrimônio cultural da saúde, tal como estamos trabalhando neste artigo.

\footnotetext{
Independentemente de manterem ou não os usos para os quais foram concebidos originalmente, muitos desses edifícios vêm sendo objeto de equivocadas e descaracterizadoras intervenções, empreendidas de forma desnecessária e por absoluto desconhecimento dos valores culturais desses edifícios.

[...]

Entretanto, não é possível e nem mesmo desejável tombar todos esses bens, até mesmo porque o tombamento, desvinculado de outras ações, não é suficiente para impedir a descaracterização de um bem cultural. Talvez seja mais importante para a preservação desses bens que sejam empreendidas ações voltadas à pesquisa e à divulgação da sua importância histórica, arquitetônica e social, principalmente entre seus gestores, funcionários e usuários mais próximos, de modo a promover o reconhecimento dos seus valores culturais por aqueles que lidam cotidianamente com esses bens e que, portanto, podem efetivamente zelar pela sua preservação de maneira mais simples e direta. (Andrade, 2011, p. 140-142)
} 


\section{O papel dos cursos de Pós-Graduação e a expansão do campo}

Conforme apontado no item anterior, os estudos sobre a história das instituições e da arquitetura para a saúde tem como o resultado evidenciar as instituições de saúde, assim valorizando sua história e seu acervo - tal como proposto por Nivaldo Andrade (2011). Este papel caberá, sobretudo, aos cursos de pósgraduação, como se verá neste tópico.

Ao longo destes dez anos surgiram cursos de pós-graduação latto e strictusensu dedicados à temática do patrimônio ou incorporando este campo de estudos às suas linhas de pesquisa. Paralelamente, as pesquisas sobre história das ciências e história da saúde também abriram espaço para que novas instituições,e seus acervos, fossem estudadas, permitindo, assim, maior valorização desse patrimônio.

A cidade do Rio de Janeiro tem a maior concentração de cursos de pósgraduação (acadêmicos e profissionais) dedicados aos estudos sobre o patrimônio tanto na modalidade acadêmica, quanto na profissional. São eles: Programa de PósGraduação em Preservação e Gestão do Patrimônio Cultural das Ciências e da Saúde, da Casa de Oswaldo Cruz/Fiocruz; Preservação de Acervos de Ciência e Tecnologia, do Museu de Astronomia e Ciências Afins; Memória e Acervos, da Fundação Casa de Rui Barbosa e Gestão de Documentos e Arquivos, da Universidade Federal do Estado do Rio de Janeiro;Patrimônio, Cultura e Sociedade, da Universidade Federal Rural do Rio de Janeiro e Preservação do Patrimônio Cultural, do Instituto de Patrimônio Histórico e Artístico Nacional (IPHAN).

Esta aventura iniciou-se na década de 2010 com a criação do curso de latto sensu em Preservação e Gestão do Patrimônio Cultural da Saúde da Casa de Oswaldo Cruz; de Preservação de Acervos de Ciência e Tecnologia; e o de Memória e Acervos da Casa Rui Barbosa. Todos eles hoje se transformaram em programas de mestrado. No caso do curso de latto sensu da Casa de Oswaldo Cruz foi estruturado em 2010 e tinha como objetivo de contribuir na qualificação de profissionais da área de patrimônio cultural no estado do Rio de Janeiro. 
Essa experiência, bem-sucedida, possibilitou que os discentes associassem a diversidade do patrimônio das instituições de ciência, cultura e saúde à aplicação de métodos e de técnicas de tratamento de acervos documentais de natureza diversa, como arquivos, bibliotecas, coleções museológicas e biológicas, e bens arquitetônicos.

Em pesquisa realizada, os egressos destacaram como sendo fatores de mérito do curso o desenvolvimento de competências e habilidades técnicas que os auxiliaram na criação de atividades e mudanças de práticas profissionais, além de ter sido um apoio na inserção acadêmica, evidenciada na aprovação em cursos de mestrado e doutorado em diversas IES do estado, e na multiplicação de saberes através de aulas ministradas e/ou orientação de estágios. Um caminho natural para muitos alunos com formação em história foi seguir para o Programa de Pós-Graduação em História das Ciências e da Saúde (PPGHCS), mantido pela COC/Fiocruz desde 2001, onde desenvolveram dissertações e teses na linha de história das instituições, aprofundando os caminhos iniciados no curso de latto sensu. Tal migração de egressos do latto sensu para o strictu sensu foi ressaltada pela avaliação da CAPES como estratégia de captação de alunos, numa instituição que não mantém cursos de graduação como a Fiocruz. E as teses e dissertações ali produzidas ampliam o conhecimento sobre as instituições de saúde e contribuem para a valorização do patrimônio cultural da saúde.

A produção de dissertações, teses e pesquisas de pós-graduação dedicadas ao tema do patrimônio cultural da saúde vem sendo realizadas em diversas instituições de ensino e pesquisa do país. Dentre as instituições podemos ressaltar o Programa de Pós-graduação em Desenvolvimento Urbano, da Universidade Federal de Pernambuco (UFPE);o Programa de Arquitetura e Urbanismo da Universidade Federal do Pará (UFPA); o Mestrado em Memória Social e Patrimônio Cultural da Universidade Federal de Pelotas; o Programa de Pós-Graduação em História da Universidade Federal de Santa Maria e de Minas Gerais; o Programa de PósGraduação em História das Ciências e da Saúde, da Casa de Oswaldo Cruz/Fiocruz; o Programa de Pós-Graduação em Arquitetura da Universidade Federal do Rio de Janeiro (UFRJ); o Mestrado em Relações Etnicorraciais, do Centro Federal de Educação Tecnológica Celso Suckow da Fonseca (CEFET-Rio). As pesquisas desenvolvidas por professores destes PPG's atestam o resultado positivo na formação 
e no despertar dos alunos para o tema do patrimônio da saúde. Sob o ponto de vista do estudo da história das instituições, da arquitetura e dos valores patrimoniais dos espaços de saúde de tais localidades, as dissertações e teses privilegiaramanálises acerca de hospitais, dispensários de tuberculose e leprosários, e seus construtores e idealizadores, abarcando desde o século XVIII até meados do século XX.

Os coordenadores dos inventários do patrimônio cultural da saúde envolvidos no projeto muitas vezes iniciaram o olhar para a temática durante o processo de pesquisa e, a partir dela, propuseram o aprofundamento de algumas análises em seus respectivos cursos de Pós-Graduação. Os estudos realizados pelos alunos desses programas ampliam e dão novo élan ao trabalho iniciado no início dos anos 2000 e nos anima a continuar a pesquisar o tema depois de uma década, em que se confirmou seu ineditismo. As reflexões sobre um campo ainda não totalmente explorado pelas ciências sociais e ciências sociais aplicadas, extrapolam estudos predominantemente acadêmicos e contribuem para ações de identificação, valorização e preservação do Patrimônio Cultural da Saúde.

\section{Referências}

AMORIM, Luiz; RIBEIRO, Cecilia. "O espaço hospitalar em dois tempos: o Pronto Socorro do Recife". In: Arquitextos, São Paulo, ano 17, n. 203.03, Vitruvius, abr. 2017 <http://www.vitruvius.com.br/revistas/read/arquitextos/17.203/6524>. (ISSN 18096298) Acessado em 02 de janeiro de 2019.

ANDRADE JUNIOR, Nivaldo Vieira de. Arquitetura Moderna e as Instituições de Saúde na Bahia nas Décadas de 1930 a 1950. In: SOUZA, Christiane Maria Cruz de; BARRETO, Maria Renilda Nery. (Org.). História da Saúde na Bahia: instituições e patrimônio arquitetônico (1808-1958). Barueri, SP: Manole, 2011, p. 94-139.

BENCHIMOL, Jaime. Manguinhos do sonho a vida. Rio de Janeiro: Ed. Fiocruz; 1990.

COSTA, Renato Gama-Rosa. Los hospitales de aislamiento y elmedio urbano. El caso de Jacarepaguá, Rio de Janeiro. In: SERVIN, Lilia González. (Org.). SISTEMA ARQUITECTÓNICO DE PABELLONES EN HOSPITALES DE AMÉRICA LATINA. México: Universidad Nacional Autónoma de México, 2011.

Amora, Ana M. G. A.; COSTA, Renato Gama-Rosa; FILGUEIRAS, Sara Cabral; MAGALHAES, C. Colonia Juliano Moreira para enfermedades mentales, actual Instituto Municipal de Asistencia a laSalud Juliano Moreira. In: Maria Lila González de Servin. (Org.). Registro del sistema arquitectónico da pabellonesenhospitales de 
América Latina. Vol. 1. 1 ed.Cidade do México: Universidad Nacional Autónoma de Mèxico, 2014.

Amora, Ana M. G. A.; COSTA, Renato Gama-Rosa; QUARESMA, F.; CASALI, T. EI Hospital Colonia de Curupaity: suhistoria, sutrazadourbanistico y sus edificaciones. In: María Lilia González Servín. (Org.). Registro del Sistema arquitectónico de pabellonesenhospitales de América Latina. Vol. 2. 1ed.Cidade do México: Universidad Nacional Autonoma de Mexico, 2016.

Amora, Ana M. G. A.; COSTA, Renato da Gama-Rosa; MALAQUIAS, T.; MOROUCO, M. Complejo Sanatorial de Curicica: un hospital pabellonario moderno. In: Maria Lilia González de Servin. (Org.). Registro del Sistema Arquitectónico de Pabellones en Hospitales de América Latina. 1ed.Cidade de Mexico: Universidad Nacional Autónoma de Mexico, 2018.

CREMNITZER, Jean-Bernard. Architecture et Santé. Le temps du sanatorium en France et en Europe. Éditons Picard, 2005.

GRANATO, Marcus et LOURENÇO, Marta C. Reflexões sobre o Patrimônio Cultural da Ciência e Tecnologia na Atualidade. In: Revista Memória em Rede, Pelotas, v.2, n.4, dez.2010 / mar. 2011 - ISSN- 2177-4129.

GRANSHAW, Lindsay et PORTER, Roy. The hospital in History. Londres/New York: Routledge; 1989.

HARTOG, François. Les régimes d'historicité. Paris: Ed. du Seuil; 2003.

MIRANDA, Cybelle Salvador; COSTA, Renato G. R. (Org.). Hospitais e saúde no Oitocentos: Diálogos entre Brasil e Portugal. 1. ed. Rio de Janeiro: FIOCRUZ, 2018, 224p.

MIRANDA, Cybelle S., MONTEIRO, Marcia R. Arquitetura assistencial e saúde: discutindo concepções e protagonistas. In: Thésis, Rio de Janeiro, v. 2, n. 3, p. 180197, jan./out. 2017.

MIRANDA, Cybelle Salvador; BELTRÃO, Jane Felipe; HENRIQUE, Márcio Couto; BESSA, Brena Tavares. Santa Casa de Misericórdia e as políticas higienistas em Belém do Pará no final do século XIX. In: História, Ciências, Saúde-Manguinhos (Impresso), v. 22, p. 00-00, 2015.

MIURA, Priscila Miyuki. Quadrilátero da Saúde: patrimônio edificado da Universidade de São Paulo - USP. In: Revista CPC, São Paulo, n. 18, p. 56-80, dez.2014/abril 2015.

PARECER da Secção de História da Medicina da Sociedade de Geografia de Lisboa. Salvaguarda do Património Cultural da Colina de Santana. Lisboa, 4 de fevereiro de 2014. 
RIBEIRO, E. S. Museus em Universidades Públicas: entre o campo científico, o ensino, a pesquisa e a extensão. In: Revista Museologia \& Interdisciplinaridade, v. 2, p. 88-102, 2013.

SERRES, Juliane Conceição Primon. Preservação do patrimônio cultural da saúde no Brasil: uma questão emergente. In: História, Ciências, Saúde - Manguinhos, Rio de Janeiro, v.22, n.4, out.-dez. 2015, p.1411-1426.

SERRES, Juliane Conceição Primon et BORGES, Viviane Trindade. Leprosários ao Sul do Brasil de locais de sofrimento a lugares de memória. In: Acervo, Rio de Janeiro, v. 28, n. 2, p. 252-263, jul./dez. 2015 - p. 252-263.

SANGLARD, Gisele.; COSTA, Renato da Gama-Rosa. Direções e traçados da assistência hospitalar no Rio de Janeiro (1923-31). História, Ciências, Saúde Manguinhos, Rio de Janeiro, v. 11, n.1, p. 107-141, 2004.

SANGLARD, Gisele.; Costa, Renato da Gama-Rosa; MELLO, Maria Tereza Villela Bandeira de. A coleção Porto d'Ave e a Assistência Hospitalar no Rio de Janeiro 1920. In: Revista do Instituto Histórico e Geográfico Brasileiro, v. 435, p. 195-208, 2007.

SANGLARD, Gisele.; COSTA, Renato Gama-Rosa. ARQUITETURA PARA SAÚDE NO ACERVO DO ARQUIVO DA CASA DE OSWALDO CRUZ. In: Fórum Patrimônio: Ambiente Construído e Patrimônio Sustentável (UFMG. Online), v. 5, p. 24-35, 2012. 